\title{
Discussion on the Innovation of Museum Cultural Communication Mode in the Post-digital Era
}

\author{
Chen Wang ${ }^{1, *}$ \\ ${ }^{1}$ Fuzhou University of International Studies and Trade, Fuzhou, Fujian, China \\ *Corresponding author. Email: 376300207@qq.com
}

\begin{abstract}
In 2014, two scholars (Bowen and Giannini, 2014) discussed how digitalization will change every aspect of human life and fundamentally alter people's behavior, knowledge, and even ways of being in the book "Digitalism: New Realism". Combined with the reality, it is easy to see that digitalization is developing much faster than its opponents expected. Currently, digitalization has spread in all walks of life around the world. It is gradually becoming a major driving force in constructing disciplines such as medicine, science, and art. In the context of the above research, this paper addresses aspects of museum digitization that cross social and cultural boundaries, break the isolation and helplessness of elitism and privilege, and challenge the design of information data architecture and interactive communication in online exhibitions, through research methods such as literature crawling. It concludes that the traditional roles of artists, visitors, and curators have substantially changed in museums' digitalization.
\end{abstract}

Keywords: Digitization, Digital museum, Artist, Audience, Curator.

\section{INTRODUCTION}

Recently, the COVID-19 pandemic has swept the world arbitrarily and gradually formed a trend of normalization. The global service industry has shown a downturn as a whole, and the total trade volume has hit a record low in the 1990s. The International Association of Museums released Investigation Report on Museums, Museum Practitioners and the COVID-19 Epidemic, an overall survey report on global museums and related practitioners in the post-epidemic era, which shows that currently there are 1,600 museums and staff of nearly 107 countries and regions in the world have been affected by the epidemic. [1] About $13 \%$ of museums have plans to lay off staff in the future. The impact of the epidemic will not only affect professional workers, but also the overall impact of the museum cannot be ignored. The constant impact is leading to $85 \%$ of museums announcing significant reductions in related activities, $90 \%$ of museums temporarily closed, and nearly $14 \%$ of museums may face permanent closure due to funding problems. Therefore, under the dual effects of rapid technological changes and the COVID-19 pandemic, digitalization has long become an important strategic policy in museum operations. In today's world, digitalization redefines the code of human behavior information and dominates the exchange of human activities and sharing, more and more dynamic portals, digital archives, social networks, blogs and online games have appeared [1]. In the accelerated process of the digital revolution, the museum's work has begun to lean towards digital media, gradually integrating and becoming digitization and interdisciplinary ecosystem, making the professions and disciplines from arts and humanities to computer science and technology more complex. Digital media is no longer an option for museums, but has been carved into the genes of museum evolution.

At present, the museum is trying to continuously widen the border, breaking the limitations of elitism, privileges, and time and space, so that artists, audiences, curators, etc., play a vital role in the overall development of the museum. They can embrace with a new look the new challenges of the post-epidemic times [2]. 


\section{REDEFINING THE ROLE OF THE ARTIST}

Nowadays, driven by a computer-centric digital culture, museums are transforming into a multifunctional place where information and content are delivered to offline, online and ubiquitous visitors. With the continuous advancement of this kind of digital, installation and hybrid new media, artists have begun to constantly try to create digital art and change the way museums and related art works attract audiences. At the moment, most artists have begun to use computers to create, and it has become the most common medium between artists and artistic realization of creativity [11]. Technically speaking, the use of computer technology is actually the use of digital technology. Digital art mainly includes any artistic work created and displayed using computer software programs. From a technical perspective, computer technology is also a digital technology, so it can also be considered as the most basic form of digital art [11]. The significance of digital art's viewing and reconstruction of the subject of art is mainly reflected in two levels: on the one hand, we use computers as a technical and display means to transform the past aesthetic experience and paradigm, so that we can see the new art world. On the other hand, the new types of knowledge represented by computer art itself constantly inspire us to think about its relevance to other disciplines. This is not only reflected in the use of computers to create works of art with independent aesthetic value (fractal art), it also shows that it can provide us with a new artistic perspective, which is quite enlightening. At the same time, it also highlights the important role of computer technology for new media art through a diachronic perspective. It can be said that it has changed our attitude to "see" art to a large extent, changed the aesthetic way between us and art, and created new platforms and new opportunities. [3]

In retrospect, the recent series of world-class museum exhibitions held in New York, London and Paris, it is not difficult to see that these museums have selected a group of artists who are familiar with today's new trends and digital art to showcase their works. Their work penetrates the society and cultural issues, which have changed the traditional way of thinking in art, and often take social consciousness, activism, daily life and other prominent themes as examples, showing the changes in art and exhibitions as the digital world has developed from the 1960 s to the present. In addition, it also focuses on the art revolution brought about by the Internet and digitalization, such as how to use the Internet to obtain information and images, create virtual communities, and discuss in depth how to create and perceive virtual selves in art and the Internet. Curator Eva Respini pointed out: "Digitization introduces a new way of viewing and being-it affects our shopping, eating, dating, traveling, social behavior and how we create and reflect on art" [4]. For example, the "Open Access Program" of the Metropolitan Museum of America provided approximately 406,000 artworks from its online collections, which greatly increased the number of art collections on the Internet. These artworks were used to support scholarships and creative work to stimulate People's reimagining of works. Network and educational software developer Simone Seagle used this open access collection to create animations of some master paintings that actually brought digital life into paintings, creating new ways to view these paintings. The large-scale digitization of artworks is using and reusing artworks in unprecedented ways. Although we cannot know how these artists reimagined their works as animated GIFs, this does not seem to be the point, which is to encourage the use of new digital ways to look at old works in new ways. In addition, in the past few years, the artist David Hockney (David Hockney) created a series of digital art works, and achieved remarkable results. From the perspective of digital art, his recent paintings exhibited at Tate Modern (2016) and the Metropolitan Museum (Met, 2017) show that he is influenced by digital art and the use of color, and his use is brighter, more intense tones, and point the creative theme to the interaction between physical aesthetics and digital aesthetics. Since the 1950s, the ever-developing digital age has changed the lives of human beings. We are worried about health problems such as being faked, losing privacy, isolation, depression, and addiction. At the same time, networking and digitalization have brought many positive aspects, such as free access to knowledge exchange, interaction and sharing, and the promotion of democracy and equality. Therefore, in addition to providing artists with a new creative platform, digitalization and the Internet also provide many new creative themes, aiming to faithfully display the confusion and challenges of the digital age. In the process of seeking to meet these challenges, people continue to growing up and discovering new human lifestyles. In the era of digital proliferation, from gender and sexual life to true self-awareness, 
people struggling for identity are drifting in the sea of computing. This view emphasizes how digital culture leads to human a fundamental change in the way of looking at one's world, thinking and seeking information has now evolved into a nonlinear and non-hierarchical model that can handle complex dichotomy, diversity and dimensions. The new multi-faceted state does not oppose the dichotomy, but becomes part of the evolving state of human complexity [6]. For example, Jerome Robbins (1918-1998) [6] , has experienced with us the integration of duality between the physical world and the virtual world of the Internet, human information behavior, the changes in art and aesthetics relationships, driven by our digital ecosystem that connects all things and life, we find ourselves in a "post-digital" world. With this in mind, Omar Kholeif wrote in the chapter Art in the Internet Age, from 1989 to Today of his exhibition catalog: "It is in the context of this duality of the Internet that brought me back to the most primitive state of art, and the invention of the Internet embodies a brand-new view of art." [7]

\section{REDEFINING THE ROLE OF THE AUDIENCE}

In the context of digital and Internet, museums are transforming into an emerging digital ecosystem, in which museums are coded as two interconnected existences of the Internet $(\mathrm{IoL})$ and the Internet of Things (IoT). The state, the core of this transition, is precisely because the museum has gradually changed from a collection-centric model to an audience-centric model that responds to human behavior, identity and cultural appreciation in the digital age. Although this shift from a usercentric model to a digital culture may be costly, it will face greater risks if it does not move in this direction in time. As museums redefine and redesign the space, they are grasping opportunities to strengthen the close relationship with the audience, and strive to develop new connections with the public's values, social and cultural behaviors and identities, so that they can penetrate into the dynamics and diversification of contemporary life while stimulating the enthusiasm of public participation. The role of the audience is redefined in this context. It can be said that the exhibition model of "human-oriented" concept coincides with the concept of "user first" in interaction design. For example, Jon Kolko defined an interaction designer as a "shapers of behavior". The core of interaction is to form an intimate dialogue between products, systems, services, and people [2]. At present, museums are using the diversified materials provided by digitization and the Internet, trying to gradually improve the experience of use and solve problems in the process of building a digital ecosystem, and creatively reconstruct content and ideas into external forms in an unexpected way, and change the venue, method and content that the audience watched, and finally resonated more deeply with the audience [8].

The original meaning of the museum often has an "elitism" color. The museum was born out of the rare room of the nobles. The earliest exhibition was just a small gathering of princes and nobles, with obvious privacy, which is completely different from the current visit mode [9]. To put it simply, the continuous openness of the right to speak in the Internet age has continued to weaken the boundaries between professionals and amateurs, elites and the general public. The establishment of a digital ecosystem has made it impossible to ignore the power of audience roles in exhibitions that have been converted from offline to online. A cooperative concept of collaboration was proposed[2], at this time, the key function of "museum" is not for science popularization and education. It is more a symbol of power and wealth. This is also the reason why museums are considered to be ideological and authoritative institutions that have long overridden the public. Today, the important function of the museum is to attract more target audiences from all walks of life, different communities, regions and groups. It should provide opportunities for general districts, special crowds and groups to support their special goals and policies. [14]. With the overflow of digital media displays and installations in daily life, people are experiencing a gallery-like environment, just as department stores and other public places that imitate museums, and life imitates artworks as well. Life in the fast lane of digital culture makes people immerse in a visual environment full of digital colors, sounds and dynamic images [10]. These are more and more reflected in the real space of city streets and other places. They are connected to the shared platform of our digital ecosystem and museums. Museums not only need to recognize these connections, they should also use them to build communities and social networks, so as to connect a wider audience, exchange information and raise awareness of the exhibition and its surrounding activities. Pursuing these goals, museums will be able to touch visitors in an inspiring and life-changing way. Museums have withdrawn from the elitist model of the past and 
entered the field of digital culture, that is, audiences have gained more power to acquire and choose independently. Now, this is a question about how to create an exhibition. Whether it is a historical exhibition or a contemporary exhibition, it can be understood from the digital perspective of the 21st century. In addition, the openness of the right to speak also means that the audience can travel anywhere, anytime in the database of the museum. In this process, the audience is not only the receiver of knowledge, but also the builder who independently selects and absorbs knowledge according to their own needs and characteristics. Compared with the pre-digital era, the monopoly of collection information by the elite has been broken, the past art works are no longer mystified, and the museum is no longer exclusive to the elite.

\section{REDEFINING THE ROLE OF THE CURATOR}

As the roles of artists and audience groups change, the functions of curators in the context of digitalization are also changing. It is easy to find that digitalization is diluting the sole authority in traditional offline museums. When the museum's ecosystem is established, the audience group continues to expand, the exhibits continue to be transparent, and the data continues to be complete. All these have given the audience and the authority almost equal interpretation power. The curator is no longer the only builder of the knowledge system, but is transformed into a sharer of information. The audience is no longer just a passive receiver of information, but is now responsible for correcting misinformation, supplementing relevant information, and disseminating and sharing information[10]. Decentralized or distributed networks include audiences as autonomous bodies, and flatten the hierarchical relationship between curators and artists [11]. At the same time, museum life has been embedded in the public life of our digital ecosystem, thereby expanding the scope of the curatorial role from a single curator to a curatorial team, including digital technology supporters necessary for digital technology which provides exciting virtual reality, augmented reality, mixed media and digital media display, etc. It is worth mentioning that the broad vision of the curatorial team has promoted the creative process, including a variety of new perspectives outside the museum. When curators make full use of digital technology to mediate the way visitors interact, educate, tell stories, and convey meaning, they will find that digital museums have a greater impact on society than traditional exhibitions. From this point of view, digital museums and online exhibitions redefine the authority of original curators and traditional exhibition models.

\section{CONCLUSION}

In summary, the museum has realized a considerable part of the important role (artist, audience, curator) transformation and opened a new Internet era [12], using online media platforms to display to the public in many aspects, which not only conveys the museum's humanism caring, also further has realized the museum's missionary function for audiences of all walks of life, meanwhile, meeting the spiritual needs of the public in the post-epidemic era. The digitalization of museums presents characteristics that are more in line with the current background of the times, such as the immediacy of visits, the openness of information, the personalization of audiences, and the mass of information. At the same time, the advantages and characteristics of digitalization assist museums to give play to more diversified social functions conferred by the new era. It can maximize the satisfaction of the museum's current and future development requirements, and better assist and participate in various work of the museum. It can be said that digitization has subverted the cultural dissemination mode of museums, so how to do a good job in the application of museum digitization and systematically establish a digital ecology in the museum work system is an important development direction for future museums [13].

\section{AUTHORS' CONTRIBUTIONS} $\mathrm{Xu}$.

This article is independently completed by Rui

\section{REFERENCES}

[1] Han Fangzheng, Discussion on Museum Construction and Development under the New Coronary Pneumonia Epidemic, Issue 10 Journal of Chifeng University (Natural Science Edition)

[2] Zhang Yizhi, 2020, The Logic Strategy and Design Translation of the Quasi-Digital Exhibition - Taking the 2020 Online Graduation Exhibition of Global Art Schools as a Clue, Design and Context 05 pages 66-72 
[3] Chu Xiaoqing, Research on the Relationship between Technological Development and the Transmutation of Art Forms, Southeast University, Doctoral Dissertation

[4] Song Wenxiang, Interview on the Effectiveness and Ineffectiveness of Exhibitions in the Post-Pandemic Era 2020, Art Market Issue 09, pp. 46-47

[5] Ge Xiuzhi, 2020, Museum curation in the post-epidemic era, Art Research 04, pages 131-133

[6] Tula Giannini and Jonathan P. Bowen, 2020, Museums and Digitalism, Museums and Digital Culture New Perspectives and Research P29-34

[7] Giannini T, 2000 Web information communities, gatekeepers, gurus and users, defining new rela- tionships. In: Proceedings of the $21 \mathrm{st}$ national online meeting. Information Today, Medford, pp 119-128

[8] Yang Xuewen, 2019, Comparative Study on the Audience's Learning Effect under Traditional Display and Multimedia Display - Taking Hangzhou Museum of Arts and Crafts as an example, Zhejiang University, Master's degree thesis.

[9] Jialin Miao, 2019, Changes in viewing in the context of museum digitalization, Nanjing University, Master's degree thesis

[10] Peng Shuoting, 2019, Research on the Role of Museum Websites in the Sustainable Development of Museums - Taking the Metropolitan Museum of Art in New York as an example, Jilin University, Master's degree thesis.

[11] Chang Juke, 2020 New Media Art Form and Its Aesthetic Significance, Nanjing University, Doctoral Dissertation

[12] Han Bing, 2020, Research on Museum's Digital Media Ecological Construction, Daguan November Issue, pages 85-85

[13] Jiang Hanyun, 2017, Observation Between Fiction and Reality-The Digital Trend of Art Exhibition Jiang Hanyun;-"National Art Research" Issue 5

[14] Analysis of the content of educational essays on museums in my country from 2006 to 2010
Cheng Yuanyuan; Liu Peng;-Software Guide

(Educational Technology)-2011 